J. Dispersion Science and Technology, 22(5), 485-489 (2001)

\title{
Extraction and Dispersion of L arge Gold Nanoparticles in Nonpolar Solvents
}

\author{
R. Balasubramanian, J un Xu, Beomseok Kim, \\ Bryce Sadtler, and Alexander Wei*
}

Department of Chemistry, Purdue University, 1393 Brown Building,

West Lafayette, IN 47907-1393

\begin{abstract}
Gold nanoparticles up to $70 \mathrm{~nm}$ in diameter could be extracted from aqueous solutions into nonpolar organic solvents by tetrathiolated resorcinarenes 1 and 2 . The resorcinarene-coated nanoparticles formed stable dispersions in toluene and chloroform and could be passed through a crosslinked polystyrene column without significant degradation, but exhibited variable resistance to alkanethiol-induced flocculation. Gold nanoparticles encapsulated by resorcinarene 2 were found to be exceptionally stable even in the presence of propanethiol and dodecanethiol, with an approximate dispersion half-life of one month at room temperature.
\end{abstract}

Key Words: Gold nanoparticles; Surface modification; Resorcinarenes; Flocculation; Colloidal gold; Tetrabenzylthiol resorcinarene; Tetraarylthiol; Particle extractions; Chloroform; Toluene

\section{INTRODUCTION}

Functionalized gold nanoparticles have been employed extensively as labels for biomolecular assays (1) and as components in nanostructured assemblies and devices (2). Particles in the mid-nanometer size range may be especially attractive in this regard, as their optical extinction and scattering properties change dramatically with size (3). However, their application as materials is often handi- capped by their limited dispersion, particularly in organic solvents. Chemisorptive surfactants such as alkanethiols are known to enhance particle dispersion and provide opportunities for further chemical modification (4), but gold nanoparticles beyond a certain size (about $10 \mathrm{~nm}$ ) are prone to flocculation because their van der Waals interactions can overwhelm the steric stabilization provided by typical surfactants (5). A nother factor to consider is the robustness of the surfactant layer against degradation or

*Corresponding author. E-mail: alexwei@ purdue.edu 

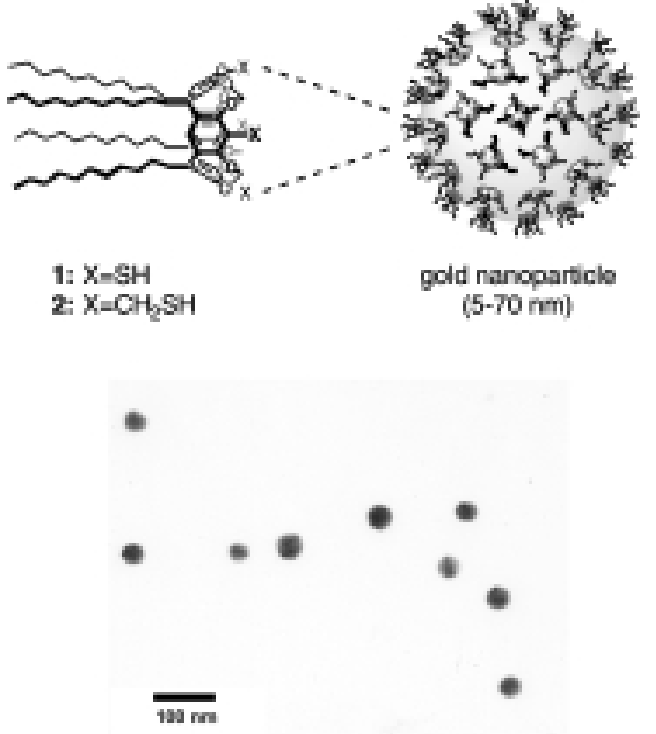

Figure 1. Gold nanoparticle encapsulated by tetrathiolated resorcinarenes. Transmission electron micrograph (Phillips EM-400, $80 \mathrm{keV}$ ) of $35 \pm 3 \mathrm{~nm}$ gold particles dispersed by 2 was obtained by placing a drop of a toluene solution onto a Formvar-coated Cu grid, then removing it a few seconds later by wicking.

desorption, as even strongly chemisorptive surfactants are known to undergo facile exchange in solution (6).

In this article we describe the enhanced robustness of gold nanoparticles stabilized by tetrathiolated resorcinarenes 1 and 2 and their dispersibility in nonpolar organic solvents (see Figure 1). Compound 2 is an exceptionally effective surfactant: it can mediate the extraction of colloidal gold particles as large as $70 \mathrm{~nm}$ from aqueous suspensions, and maintain kinetically stable dispersions in nonpolar solvents such as toluene and chloroform. We have previously demonstrated that appropriately modified resorcinarenes are excellent dispersants of gold nanoparticles in hydrocarbon solvents, but exhibit variable degrees of robustness (7). In comparison, nanoparticles encapsulated by 2 are remarkably robust, and can resist degradation or flocculation even after long-term exposure to competing alkanethiol surfactants.

\section{EXPERIMENTAL}

Resorcinarenes 1 and 2 were synthesized by modification of known literature procedures $(8,9)$. Gold nanoparticles of narrow size dispersity were prepared as aqueous suspensions by citrate reduction of gold chloride $\left(10^{10}-10^{11}\right.$ particles $\left./ \mathrm{mL}\right)(10)$, then treated with milli- molar solutions of 1 or 2 in THF. The resorcinareneencapsulated nanoparticles could be extracted into toluene or chloroform upon adding minute amounts (1-5 mol \% of surfactant concentration) of tetra-noctylammonium salts, which presumably exchange with inorganic counterions in the electrostatic double layer. Extracts were dried over molecular sieves and concentrated until optical densities between 0.1 and 0.2 were achieved at plasmon resonance $(532 \mathrm{~nm})$ (11). Dispersions of encapsulated nanoparticles with minimal free surfactant could also be prepared by washing the aqueous solution with hexanes prior to the extraction procedure above. All extractions and dispersions were performed in silanized glassware to minimize surface adsorption.

\section{RESULTS AND DISCUSSION}

Tetrabenzylthiol resorcinarene 2 was capable of extracting and dispersing gold particles as large as $34 \mathrm{~nm}$ into toluene and as large as $70 \mathrm{~nm}$ into chloroform solutions (12,13). These nanoparticle dispersions appeared to be indefinitely stable at room temperature even with the removal of excess surfactant, retaining over $90 \%$ of their optical density after one month (see below). Tetraarylthiol 1 was less effective but could still extract and disperse 19- and 42-nm gold particles into toluene and chloroform, respectively. The basis for the difference between 1 and 2 is not yet established but may be related to the surfactants' strength of adsorption. The four thiol groups of 2 are unencumbered and therefore should be able to strongly passivate the gold surface by cooperative adsorption, whereas those of 1 are sterically hindered by neighboring methylene units and may be unable to adsorb in a tetradentate fashion, resulting in weaker passivation (see Figure 2).

The resorcinarene-coated nanoparticles were evaluated by gel permeation chromatography (GPC), which has been used to provide a qualitative measure of structural stability for encapsulated nanoparticles (14)
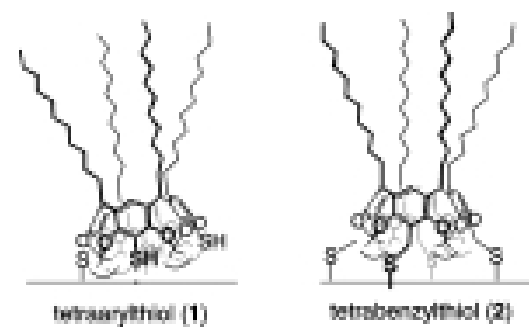

Figure 2. Steric differences between resorcinarenes 1 and 2 adsorbed on gold nanoparticle surfaces. 


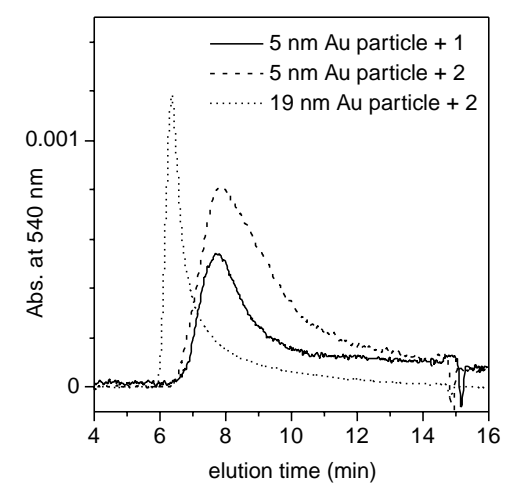

Figure 3. Gel permeation chromatography (GPC) traces of 5- and $19-\mathrm{nm}$ gold particles stabilized by 1 or 2 . Peaks were monitored by optical absorbance at $540 \mathrm{~nm}$. The abrupt change in absorbance after 15 min correlates with the elution of toluene.

and other nanostructured assemblies (15). 5- and 19-nm particles encapsulated by 1 or 2 were loaded onto a crosslinked polystyrene column (Styragel HR 4E, Waters) and eluted with chloroform at a flow rate of $0.75 \mathrm{~mL} / \mathrm{min}$. GPC peaks were produced with retention times and peakshapes in accord with their size and polydispersity and exhibited only minor tailing (see Figure 3) $(14,16)$. It is worth mentioning that the hydrodynamic volumes of the resorcinarene-encapsulated nanoparticles did not correlate well with those of polystyrene size standards as estimated by the M arc-Houwink equation (17), although this is hardly surprising given their completely different compositions. GPC analysis of nanoparticles using $0.1 \mathrm{mM}$ surfactant in chloroform as the eluent produced essentially identical peakshapes, demonstrating that the resorcinarene-encapsulated nano- particles were stable against surfactant desorption during elution.

The nanoparticle dispersions were also evaluated for long-term stability in the presence of other alkanethiol surfactants by monitoring their optical density at $532 \mathrm{~nm}$ (see Figure 4). It has been demonstrated previously that the displacement of resorcinarenes by single-chain alkanethiols would result in the flocculation of gold particles larger than $10 \mathrm{~nm}$ with a concomitant loss of optical density (7). Indeed, dispersions of 19-nm particles stabilized by 1 in toluene were degraded by the addition of propanethiol $(\mathrm{C} 3 \mathrm{SH})$ or dodecanethiol $(\mathrm{C} 12 \mathrm{SH})$ : the dispersion half-life was reduced from $214 \mathrm{hrs}(1.5$ weeks) in the absence of competing surfactant to $100 \mathrm{hrs}$ (4.2 days) in the presence of $1.7 \mathrm{mM} \mathrm{C} 3 \mathrm{SH}$ (see Figure 4a). In comparison, addition of $1-3 \mathrm{mM}$ $\mathrm{C} 3 \mathrm{SH}$ or $\mathrm{C} 12 \mathrm{SH}$ to $19-\mathrm{nm}$ gold particles stabilized by 2 caused only a gradual decrease in optical density, with an approximate dispersion half-life of one month at room temperature (see Figure 4b). Transmission electron micrographs of the resorcinarene-stabilized nanoparticles after one month exposure to PrSH indicated an intermediate degree of flocculation; however, the particles retained their individuality and were easily redispersed upon agitation. Nanoparticles dispersed by 2 in chloroform exhibited similar levels of robustness. It should be noted that nanoparticles encapsulated by 2 were also stable to other chemisorptive agents such as $\mathrm{PPh}_{3}$ and could withstand heating to at least $70^{\circ} \mathrm{C}$, but were vulnerable to oxidation by iodine and degradation by corrosive ions such as cyanide and fluoride.

In summary, we have developed a methodology for enhancing the dispersibility and robustness of gold nanoparticles up to $70 \mathrm{~nm}$ in organic solvents and in
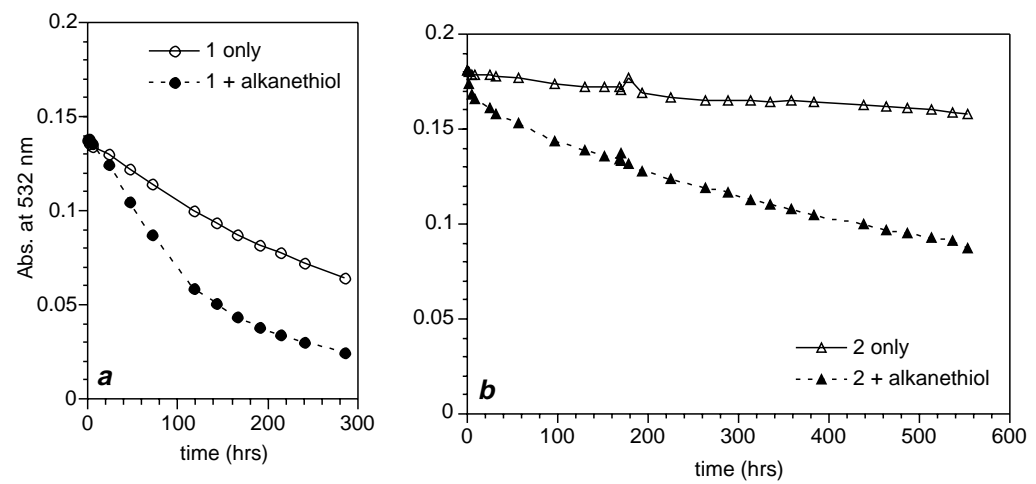

Figure 4. Dispersion stability studies of resorcinarene-encapsulated gold nanoparticles. (a) 19-nm gold particles stabilized by 1 in toluene $(1.8 \mathrm{mM})$ in the absence and presence of $\mathrm{C} 3 \mathrm{SH}(1.7 \mathrm{mM})$. (b) $19-\mathrm{nm}$ gold particles stabilized by 2 in toluene $(2 \mathrm{mM})$ in the absence and presence of $\mathrm{C} 3 \mathrm{SH}(1.7 \mathrm{mM})$. A dditional alkanethiol (C12SH, $1.7 \mathrm{mM})$ was added after one week. 
the presence of competing surfactants. Surfactants such as resorcinarenes 1 or 2 should provide increased processing control for dispersing larger nanoparticles into polymer-matrix composites and in the fabrication of ordered nanostructured materials, as recently demonstrated by the self-organization of large gold nanoparticles into planar arrays (18). The superior dispersive properties of the resorcinarenes may also be useful for other nonaqueous particulate systems which require enhanced steric stabilization, such as electro- and magnetorheological fluids (19).

\section{ACKNOWLEDGEMENTS}

The authors gratefully acknowledge the National Science Foundation (BES-0086804) and the Research Corporation Innovation Award program (RI-0333) for financial support. TEM images were taken at the Purdue Life Sciences M icroscopy Facility. The authors thank Steven Tripp for supporting particle characterization by transmission electron microscopy and Prof. Ronald A ndres for helpful discussions.

\section{REFERENCES}

1. (a) Colloidal Gold: Principles, Methods, and Applications; Hayat, M. A., ed.; Academic Press: San Diego, 1989; Vols. 1-3. (b) Elghanian, R.; Storhoff, J. J.; M ucic, R. C.; Letsinger, R. L.; M irkin, C. A. Selective Colorimetric Detection of Polynucleotides Based on the Distance-Dependent Optical Properties of Gold Nanoparticles. Science 1997, 277, 1078-1081.

2. (a) Simon, U.; Schön, G.; Schmid, G. The A pplication of $\mathrm{A} \mathrm{u}_{55}$ Clusters as Quantum Dots. A ngew. Chem. Int. Ed. Engl. 1993, 32, 250-254. (b) Brust, M.; Bethell, D.; Schiffrin, D. J.; Kiely, C. J. Novel Gold-Dithiol NanoNetworks with Non-M etallic Electronic Properties. Adv. M ater. 1995, 7, 795-797. (c) A ndres, R. P.; B iel efeld, J. D.; Henderson, J. I.; Janes, D. B.; Kolagunta, V. R.; Kubiak, C. P.; M ahoney, W. J.; Osifchin, R. G. Self-A ssembly of a Two-Dimensional Superlattice of Molecularly Linked M etal Clusters. Science 1996, 273, 1690-1693. (d) A livisatos, A. P.; Johnsson, K. P.; Peng, X.; Wilson, T. E.; L oweth, C. J.; B ruchez, M. P., J r.; Schult, P. G. Organization of 'nanocrystal molecules' using DNA. Nature 1996, 382, 609-611. (e) Keating, C. D.; M usick, M. D.; Lyon, L. A.; Brown, K. R.; Baker, B. E.; Pena, D. J.; Feldheim, D. L.; M allouk, T. E.; Natan, M. J. NanometerScale A rchitecture U sing Colloidal Gold. In ACS Symp. Ser. 679: Nanostructured Materials; Shalaev, V. M.,
Moskovits, M., Eds.; American Chemical Society: Washington, DC, 1997; Vol. 679, p 7-14. (f) Storhoff, J. J.; M irkin, C. A. Programmed materials synthesis with DNA. Chem. Rev. 1999, 99, 1849-1862.

3. (a) Y guerabide, J.; Y guerabide, E. E. Light-scattering submicroscopic particles as highly fluorescent analogs and their use as tracer labels in clinical and biological applications. I. Theory. A nal. Biochem. 1998, 262, 137-156. (b) Taton, T. A.; Lu, G.; Mirkin, C. A. Twocolor Labeling of Oligonucleotide Arrays via Sizeselective Scattering of Nanoparticle Probes. J. A m. Chem. Soc. 2001, 123, 5164-5165.

4. (a) Brust, M.; Fink, J.; Bethell, D.; Schiffrin, D. J.; Kiely, C. Synthesis and Reactions of Functionalized Gold Nanoparticles. J. Chem. Soc. Chem. Commun. 1995, 1655-1656. (b) Templeton, A. C.; Hostetler, M. J.; Kraft, C. T.; M urray, R. W. Reactivity of M onolayerProtected Gold Cluster Molecules: Steric Effects. J. A m. Chem. Soc. 1998, 120, 1906-1911. (c) Watson, K. J.; Zhu, J.; N guyen, S. T.; M irkin, C. A. Hybrid Nanoparticles with Block Copolymer Shell Structures. J. Am. Chem. Soc. 1999, 121, 462-463.

5. Israelachvili, J. Intermolecular and Surface Forces; 2nd ed.; A cademic Press: N ew York, 1992; Chapter 10.

6. Schlenoff, J. B.; Li, M.; Ly, H. Stability and SelfExchange in Alkanethiol Monolayers, J. Am. Chem. Soc. 1995, 117, 12528-12536.

7. (a) Stavens, K. B.; Pusztay, S. V.; Zou, S.; A ndres, R. P.; Wei, A. Encapsulation of Neutral Gold Nanoclusters by Resorcinarenes. Langmuir 1999, 15, 8337-8339. (b) Wei, A.; Stavens, K. B.; Pusztay, S. V.; Andres, R. P. Synthesis and Characterization of Resorcinarene-Encapsulated Nanoparticles. M RS Symp. Proc. Ser. 1999, 581, 59-63.

8. (a) Moran, J. R.; Karbach, S.; Cram, D. J. Cavitands: Synthetic Molecular Vessels J. Am. Chem. Soc. 1982, 104, 5826-5828. (b) Cram, D. J.; Karbach, S.; K im, H.-E.; K nobler, C. B.; M averick, E. F.; Ericson, J. L.; Helgeson, R. C. Host-Guest Complexation. 46. Cavitands as Open Molecular Vessels Form Solvates. J. A m. Chem. Soc. 1988, 110, 2229-2237. (c) Gibb, B. C.; Mezo, A. R.; Causton, A. S.; Fraser, J. R.; Tsai, F. C. S.; Sherman, J. C. Efficient coupling of amino acid derivatives to rigid organic scaffolds: model syntheses for de novo proteins. Tetrahedron 1995, 51, 8719-8732.

9. Cram, D. J.; Karbach, S.; Kim, Y. H.; Baczynskyj, L.; K alleymeyn, G. W. Shell Closure of Two Cavitands Forms Carcerand Complexes with Components of the Medium as Permanent Guests. J. Am. Chem. Soc. 1985, 107, 2575-2576.

10. (a) Turkevich, J.; Stevenson, P. C.; Hillier, J. A study of the nucleation and growth processes in the synthesis of colloidal gold. Disc. Farad. Soc. 1951, 11, 55-75. (b) Frens, G. Controlled Nucleation for the Regulation 
of the Particle Size in M onodisperse Gold Suspensions. Nature Phys. Sci. 1973, 241, 20-22. Citrate-stabilized gold nanoparticles of narrow size dispersity were also obtained from British Biocell International.

11. THF could be removed azeotropically by repeated rotary evaporation with toluene, with minimal effect on dispersion stability.

12. All diameters were determined as statistical averages by particle size analysis of transmission electron micrographs with coefficients of variance between $10-15 \%$.

13. Gold nanoparticles up to $100 \mathrm{~nm}$ could be extracted into $\mathrm{CHCl}_{3}$ by resorcinarene 2 with higher concentrations of tetra-n-octyl ammonium bromide $(0.2 \mathrm{mM})$. However, these dispersions were more limited in their stability.

14. Wilcoxon, J. P.; M artin, J. E.; Provencio, P. Size distributions of gold nanoclusters studied by liquid chromatography. Langmuir 2000, 16, 9912-9920.

15. (a) Whitesides, G. M .; Simanek, E. E.; P., M . J.; Seto, C. T.; Chin, D. N.; M ammen, M.; Gordon, D. M. Noncovalent Synthesis: Using Physical-Organic Chemistry to Make
Aggregates. Acc. Chem. Res. 1995, 28, 37-44. (b) Zimmerman, S. C.; Zeng, F.; Reichert, D. E. C.; Kolotuchin, S. V. Self-A ssembling Dendrimers. Science 1996, 271, 1095-1098.

16. Peak tailing may be an indication that the nanoparticles adsorb weakly to the GPC column. The narrow and unsymmetrical peakshape produced by the 19-nm particles suggests that their retention is at or beyond the sizeexclusion limit of the polystyrene column.

17. Encyclopedia of Polymer Science and Engineering, 2nd ed.; M ark, H. F., Bikales, N. M., Overberger, C. G., Menges, G., K roschwitz, J. I., Eds.; John Wiley: New York, 1985; Vol. 3.

18. Kim, B.; Tripp, S. L.; Wei, A. Self-Organization of Large Gold Nanoparticle A rrays. J. A m. Chem. Soc. 2001, 123, 7955-7956.

19. Rankin, P. J.; Ginder, J. M .; Klingenberg, D. J. Electroand magneto-rheology. Curr. Op. Colloid Interface Sci. 1998, 3, 373-381.

Received: A ugust 5, 2001

A ccepted: A ugust 13, 2001 